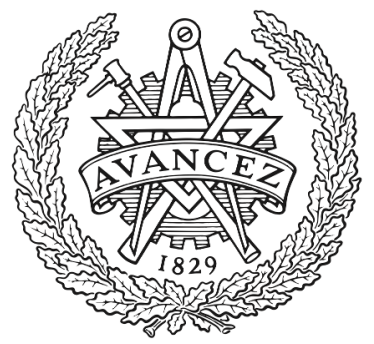

CHALMERS

UNIVERSITY OF TECHNOLOGY

\title{
Order-Disorder Transition in Inorganic Clathrates Controls Electrical Transport Properties
}

Downloaded from: https://research.chalmers.se, 2023-04-26 12:04 UTC

Citation for the original published paper (version of record):

Brorsson, J., Zhang, Y., Palmqvist, A. et al (2021). Order-Disorder Transition in Inorganic Clathrates Controls Electrical Transport Properties. Chemistry of Materials, 33(12): 4500-4509.

http://dx.doi.org/10.1021/acs.chemmater.1c00731

N.B. When citing this work, cite the original published paper. 


\title{
Order-Disorder Transition in Inorganic Clathrates Controls Electrical Transport Properties
}

\author{
Joakim Brorsson, Yifei Zhang, Anders E. C. Palmqvist, and Paul Erhart* \\ Cite This: Chem. Mater. 2021, 33, 4500-4509 \\ Read Online
}

ABSTRACT: Inorganic clathrates have been extensively investigated owing to their unique and intriguing atomic structure as well as their potential as thermoelectric materials. The connection between the chemical ordering and the physical properties has, however, remained elusive. Here, this relation is uncovered through a combination of first-principles calculations, atomistic simulations, and experimental measurements of thermodynamic as well as electrical transport properties. This approach is, specifically, used to reveal the existence of an order-disorder transition in the quaternary clathrate series $\mathrm{Ba}_{8} \mathrm{Al}_{x} \mathrm{Ga}_{16-x} \mathrm{Ge}_{30}$. The results, furthermore, demonstrate that this phenomenon is responsible for the discontinuity in the heat capacity that has been observed

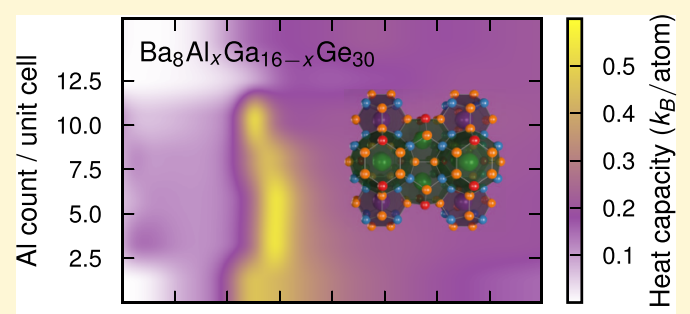

200300400500600700800 Temperature $(\mathrm{K})$ previously. Moreover, the unusual temperature dependence of both Seebeck coefficient and electrical conductivity can be fully explained by the alterations of the band structure brought about by the phase transformation. It is finally argued that the phenomenology described here is not limited to this particular material but should be present in a wide range of inorganic clathrates and could even be observed in other materials that exhibit chemical ordering on at least one sublattice.

\section{INTRODUCTION}

Since their discovery, inorganic clathrates have fascinated and intrigued the scientific community because of their complex crystal structure and interesting physical properties. ${ }^{1-3}$ Their usefulness for thermoelectric applications was recognized, when it was hypothesized, and later proven, that semiconducting materials with host-guest structures could be potential realizations of the "phonon glass-electron crystal" concept. ${ }^{4}$ The most relevant and well-studied members of this group consist of alkali or alkaline earth "guest" atoms that are trapped inside a "host" framework, made up of elements from groups 13 and 14 of the periodic table. ${ }^{2,3}$ In this study, we consider a type I clathrate, which is by far the most widely explored subclass. This collection of materials belongs to space group $\mathrm{P} m \overline{3} n$ (international tables of crystallography number 223) and is represented by the chemical formula $A_{8} B_{x} C_{46-x}$ where $\mathrm{A}$ corresponds to the guest, while $\mathrm{B}$ and $\mathrm{C}$ are host species. The structure consists of a framework that incorporates two types of cages in the form of large pentagonal dodecahedra and smaller tetrakaidecahedra, which are centered at Wyckoff sites $6 d$ and $2 a$, respectively (Figure 1a). Each of these cages contains a single guest atom, which is often assumed to be located at the center, while the host atoms are distributed between three sites (6c, 16i, and $24 k$ ).

Although type I clathrates have long been believed to be thermally stable, a recent study ${ }^{5}$ has revealed that this is not the case. While this investigation clearly shows that $\mathrm{Ba}_{8} \mathrm{Ga}_{16} \mathrm{Ge}_{30}$ starts to decompose at elevated temperatures, this phenomenon cannot account for all the inconsistencies in the reported high-temperature (HT) properties. $^{6-11}$ In particular, this explanation is not consistent with the fact that the transformations, which give rise to the peculiarities in the property measurements, in many instances appear to be reversible. ${ }^{7}$ Additionally, several recent studies have revealed the importance of taking structural transitions between ordered and disordered states into account when assessing the properties of various functional materials. ${ }^{12-15}$

The most compelling experimental evidence for the existence of a phase transformation presented so far is the sharp jump in the heat capacity at around $650 \mathrm{~K}$ observed by May et al. ${ }^{11}$ Several of their $\mathrm{Ba}_{8} \mathrm{Ga}_{x} \mathrm{Ge}_{46-x}$ samples also display unexpected features in the electrical resistivity, Seebeck coefficient, and thermal diffusivity at around the same temperature. It is also interesting to note that this phenomenon does not appear to be unique for $\mathrm{Ba}_{8} \mathrm{Ga}_{x} \mathrm{Ge}_{46-x}$ since similar results have been obtained for several other type I clathrates including $\mathrm{Ba}_{8} \mathrm{Al}_{x} \mathrm{Si}_{46-x},{ }^{16,17} \quad \mathrm{Ba}_{8} \mathrm{~B}_{x} \mathrm{Al}_{y} \mathrm{Si}_{46-x-y},{ }_{18}$ $\mathrm{Ba}_{8-y} \mathrm{Eu}_{y} \mathrm{Al}_{x} \mathrm{Si}_{46-x},{ }^{16} \mathrm{Ba}_{8-y} \mathrm{Sr}_{y} \mathrm{Al}_{x} \mathrm{Si}_{46-x},{ }_{19}$ and $\mathrm{Ba}_{8} \mathrm{Ga}_{x} \mathrm{In}_{y} \mathrm{Ge}_{46-x-y}{ }^{20}$ Additionally, it has been reported ${ }^{21,22}$ that the binary clathrates $\mathrm{Rb}_{8} \mathrm{Sn}_{44} \square_{2}$ and $\mathrm{Cs}_{8} \mathrm{Sn}_{44} \square_{2}$ undergo

Received: February 27, 2021

Revised: $\quad$ May 24, 2021

Published: June 3, 2021 

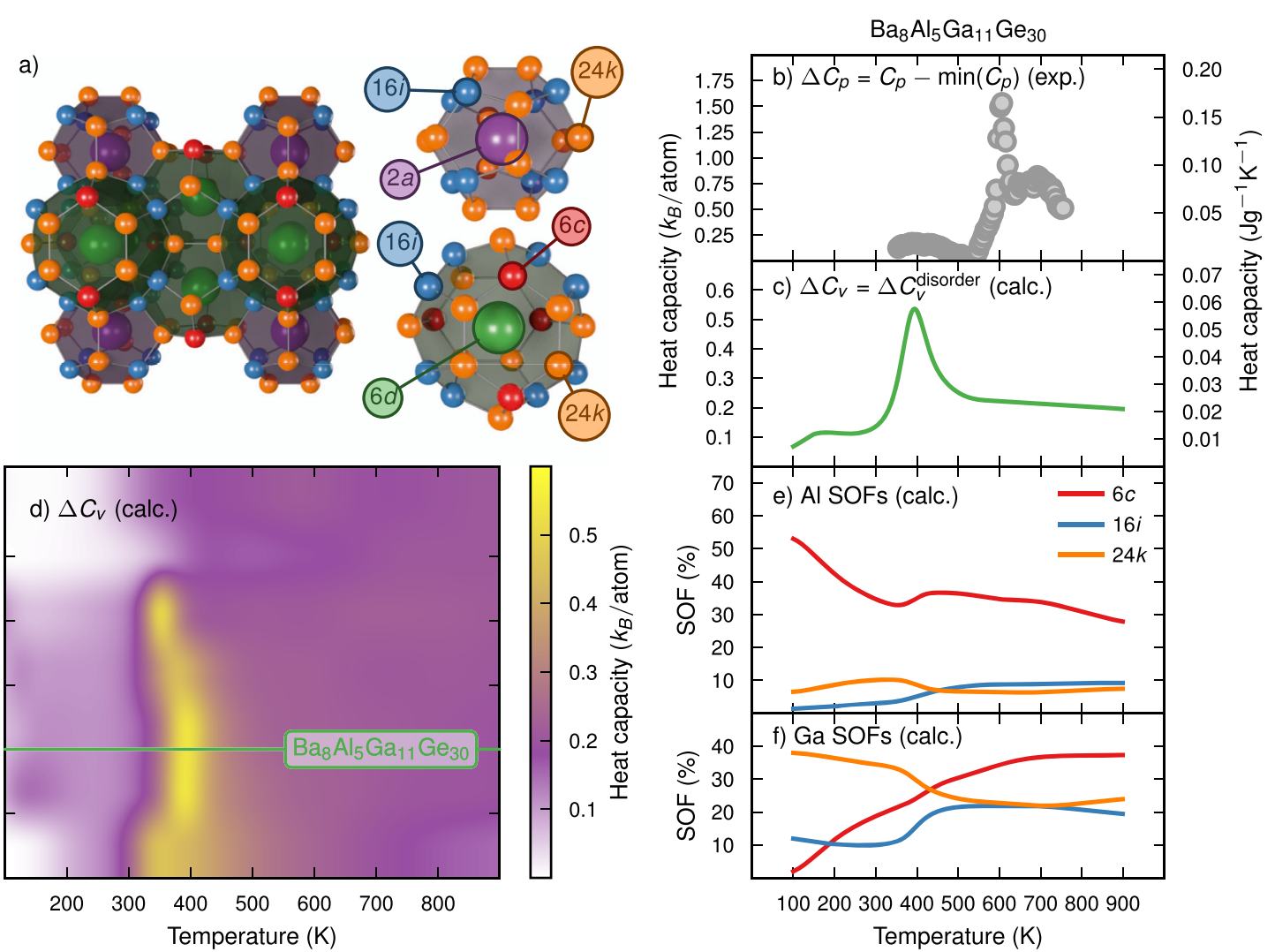

Figure 1. Experimental measurements and simulation results indicating the existence of an order-disorder transition in $\mathrm{Ba}_{8} \mathrm{Al}_{x} \mathrm{Ga}_{16-x} \mathrm{Ge}_{30}$. (a) Crystal structure of a typical type I clathrate. Purple and green spheres represent $2 a$ and $6 d$ guest sites, respectively, while the $6 c, 16 i$, and $24 k$ host sites are colored red, blue, and orange, respectively. (b) Measured heat capacity at constant pressure relative to the minimum value and (c) contribution from disorder at a constant volume as function of temperature for $\mathrm{Ba}_{8} \mathrm{Al}_{5} \mathrm{Ga}_{11} \mathrm{Ge}_{30}$. (d) Corresponding results for a range of different

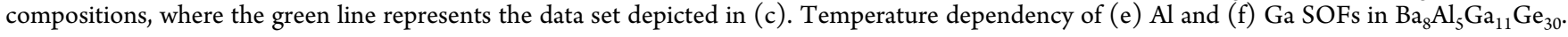

transformations between states with ordered and disordered vacancies $(\square)$ at around 353 and $363 \mathrm{~K}$, respectively, which lead to dramatic increases in the absolute values of the Seebeck coefficients. Evidence for a transition associated with order in these materials has also been provided via simulations, revealing distinct features in the heat capacity. ${ }^{23,24}$

Due to the large number of atoms per unit cell, the configurational space is extremely large ${ }^{25}$ which makes it impossible to sample with density functional theory (DFT) calculations alone. It has, however, been recently shown that this problem can be circumvented by using a combination of DFT, alloy cluster expansions (CEs), and Monte Carlo (MC) simulations. $^{23,26,27}$ These studies have, furthermore, revealed that the host site occupation factors (SOFs) not only depend strongly on both temperature and composition ${ }^{23}$ but also significantly affect the thermoelectric performance. ${ }^{26}$ In fact, the former results verified the set of rules regarding the distribution of the host atoms among the three Wyckoff sites, the most important one being the minimization of the number of bonds between trivalent atoms, which had been previously formulated based on data from diffraction experiments. ${ }^{1,28}$

Here, we use a combination of experimental and computational methods to prove the existence of an order-disorder transition above room temperature in the quaternary clathrate $\mathrm{Ba}_{8} \mathrm{Al}_{5} \mathrm{Ga}_{11} \mathrm{Ge}_{30}$. We, furthermore, show that it has an impact on the band structure and, thereby, the electrical transport properties. In what follows, we begin by describing the sample preparation before detailing the procedures for carrying out both experiments and calculations. Next, we present our main results, starting with the heat capacities and SOFs, followed by the thermoelectric properties and the band structure. Finally, we discuss the implications of our findings for not only clathrates but also other materials that exhibit temperaturedependent ordering.

\section{METHODS}

Experimental Details. Details regarding the synthesis and characterization of the $\mathrm{Ba}_{8} \mathrm{Al}_{5} \mathrm{Ga}_{11} \mathrm{Ge}_{30}$ single crystalline sample, which was prepared using the Czochralski method, will be published separately. For the property measurements, a rod-shaped sample, with a size of about $2 \times 2 \times 8 \mathrm{~mm}^{3}$, was cut from the mid-section of the crystal using a diamond saw (Struers). A ZEM-3 (ULVAC) instrument was then used to measure the electrical resistivity and Seebeck coefficient between 100 and $700{ }^{\circ} \mathrm{C}$ in a low-pressure $\mathrm{He}$ atmosphere. The sample and the platinum electrodes were separated by graphite sheets (Goodfellow Cambridge Ltd.) to hinder reaction. The sapphire method (E1269-11) $)^{29}$ was used to determine the specific heat capacity for Czochralski-pulled and flux-grown $\mathrm{Ba}_{8} \mathrm{Al}_{5} \mathrm{Ga}_{11} \mathrm{Ge}_{30}$ as well as polycrystalline $\mathrm{Ba}_{8} \mathrm{Ga}_{16} \mathrm{Ge}_{30}$ and $\mathrm{Ba}_{8} \mathrm{Al}_{16} \mathrm{Ge}_{30}$ (see Figure S2 and Supporting Information Note S2) using a differential scanning calorimetry (DSC) instrument (Mettler Toledo DSC2). Specifically, pieces from a cross-sectional slice of the crystal were placed in a $100 \mu \mathrm{L}$ aluminum crucible, the inside of which had been covered by a piece of graphite paper. During the experiment, which was performed under a $\mathrm{N}_{2}$ atmosphere, the sample was heated to $500{ }^{\circ} \mathrm{C}$ at a rate of $5 \mathrm{~K} \mathrm{~min}^{-1}$. Once finished, the specific heat $\left(C_{\mathrm{p}}\right)$ was calculated based on the second heating curve.

The determination of the composition is quite challenging since the content of the lightest element ( $\mathrm{Al})$ is less than $5 \mathrm{wt} \%$. We have therefore expended considerable effort on determining the compo- 
sition using synchrotron and single-crystal X-rays as well as both powder and single-crystal neutron diffraction in addition to scanning electron microscopy, energy-dispersive $\mathrm{X}$-ray spectroscopy, and X-ray fluorescence. This characterization indicates that the amount of $\mathrm{Al}$ is approximately $x=4.7-5.2$; for simplicity, we, therefore, refer to the sample as $\mathrm{Ba}_{8} \mathrm{Al}_{5} \mathrm{Ga}_{11} \mathrm{Ge}_{30}$. The details of these analyses will be published elsewhere.

MC and Wang-Landau Simulations. Alloy CEs in combination with $\mathrm{MC}$ simulations provide a powerful approach for combining the accuracy of first-principles calculations with the computational efficiency needed for sampling compositional degrees of freedom. They are lattice models that describe a particular chemical configuration in terms of the population of different lattice sites in the fashion of a generalized Ising model. Unlike the standard Ising model, interactions can, however, extend over many neighbor shells and involve not only pair terms but also groups of three, four or more sites. Each such cluster is associated with an effective cluster interaction that enters the mathematical expression for the total energy. By fitting these expansion coefficients to data from firstprinciples calculations, commonly based on DFT, one can obtain accurate and transferable models for the energetics of multicomponent systems. It is important to emphasize that while these models operate on a rigid lattice, atomic relaxations are effectively incorporated in the effective cluster interactions if relaxed configurations are used for training.

In this study, we have employed the ICET software package ${ }^{30}$ to train alloy CE using a set of DFT-relaxed structures (see the next section). The cutoffs for both pairs and triplets were set to be slightly smaller than half the lattice parameter $(5.4 \AA)$, yielding 215 symmetry inequivalent clusters, including 6 singlets, 46 pairs, and 162 triplets. Based on extensive testing of different fitting methods (also see ref 31), the final CE was fitted using ordinary least squares (OLS) with recursive feature elimination (RFE). In particular, this method gave consistently better results, in agreement with earlier studies, ${ }^{30}$ both in terms of root-mean-square error (RMSE) and model sparsity. This process reduced the number of non-zero parameters to 23 pairs and 5 triplets while retaining a low final RMSE score of $1.49 \mathrm{meV}$ site $^{-1}$.

To evaluate the contribution of chemical disorder to the heat capacity as well as the variation of the SOFs with temperature, the CEs where sampled via both Wang-Landau (WL) ${ }^{32}$ and standard MC simulations using the MCHAMMER module of ICET. These simulations were performed for a range of different stoichiometric compositions, namely, $\mathrm{Ba}_{8} \mathrm{Al}_{x} \mathrm{Ga}_{16-x} \mathrm{Ge}_{30}$ with $x \in\{0,4,6,8,12,16\}$, using $1 \times 1 \times 1$ and $2 \times 2 \times 2$ supercells. It was not deemed worthwhile to consider larger sizes since this causes severe convergence issues and, at the same time, only leads to a relatively small shift in the transition temperature (see Figure S3 and Supporting Information Note S3).

The WL simulations were carried out using an energy spacing of 50 $\mathrm{meV}$ until the fill factor, which was updated each time the flatness of the energy histograms reached more than $80 \%$, dropped below $10^{-7}$. Since the WL method requires a very large number of MC steps, it was moreover necessary to divide the energy range into a number of bins, which were converged in parallel. When using the MC method, meanwhile, a canonical ensemble was employed and the simulations were carried out by reducing the temperature from 1200 to $0 \mathrm{~K}$ at a rate of $100 \mathrm{~K}$ per $22,000 \mathrm{MC}$ cycles.

Electronic Structure Calculations. In preparation of the construction of the alloy CEs (see the previous section), 528 randomly generated $\mathrm{Ba}_{8} \mathrm{Al}_{x} \mathrm{Ga}_{y} \mathrm{Ge}_{46-x-y}$ structures, which included $132 \mathrm{Ba}_{8} \mathrm{Ga}_{x} \mathrm{Ge}_{46-x}$ and equally many $\mathrm{Ba}_{8} \mathrm{Al}_{x} \mathrm{Ge}_{46-x}$ configurations, were relaxed, with regard to both cell metric and ionic positions, at the level of DFT as implemented in the Vienna ab initio simulation package (VASP $)^{33}$ using the projector augmented wave (PAW) method. ${ }^{34,35}$ These calculations were considered converged once the maximum residual force was below $5 \mathrm{meV} \AA^{-1}$. $\Gamma$-Centered $3 \times 3 \times 3$ $k$-point meshes, Gaussian smearing with a width of 0.1 , and $319 \mathrm{eV}$ plane wave energy cutoffs were used for all calculations. The van der Waals density functional method ${ }^{36}$ with consistent exchange (vdW$\mathrm{DF}-\mathrm{Cx})^{37}$ was employed to account for exchange-correlation effects.
Calculations of Electronic Properties. To assess the impact of the order-disorder transition on the electronic transport properties and the band structure, we extracted the ground-state (GS) and HT structures from standard MC simulations. In particular, the former was identified as the $1 \times 1 \times 1$ configuration, among those sampled across the entire temperature range, with the lowest energy. The HT state, on the other hand, was represented via special quasi-ordered structures $^{38}$ by constructing a primitive structure that closely corresponds to the average cluster vector obtained using $2 \times 2 \times 2$ supercells at $1200 \mathrm{~K}$. Note that this approach gives similar results to calculating statistical averages over multiple representative structures (see Figure S6 and Supporting Information Note S5).

Prior to calculating the transport properties, the extracted structures were first relaxed using similar settings to those described in the previous subsection with the exception that a $5 \times 5 \times 5 k$-point grid was employed and that the convergence criteria were tightened by a factor of 10 . This was followed by a non-self-consistent calculation using an interpolated $\Gamma$-centered $25 \times 25 \times 25$ mesh. A similar procedure was performed to determine the band structure, although a sparser grid, with $3 \times 3 \times 3 k$-points, was used and a total of 512 electronic bands were taken into consideration. Since semilocal exchange-correlation functionals underestimate the band gap, we computed band gaps using the modified Becke-Johnson (mBJ) metafunctional, which were subsequently used to set the scissor correction in the Boltzmann transport theory (BTT) calculations (see below). ${ }^{39,40}$

The transport coefficients were calculated within the framework of BTT at the relaxation time approximation (RTA) level using the interpolated eigenenergies as well as the group velocities as input to the BoltzTraP2 ${ }^{41}$ software. The variation of the relaxation time with temperature was assumed to follow a simple power law, $\tau_{\text {eff }}=$ $\tau_{300 \mathrm{~K}}(300 \mathrm{~K} / \mathrm{T})^{a}$, where $\tau_{300 \mathrm{~K}}$ corresponds to the value at $300 \mathrm{~K}$. The parameters $\tau_{300 \mathrm{~K}}$ and $a$ were determined for each composition by fitting the electrical conductivity, calculated for the GS, to the experimental measurements below $650 \mathrm{~K}$ (see Table S1 and Supporting Information Note S5). The optimal doping level, meanwhile, was selected so as to give the best possible agreement between the calculated and experimental Seebeck coefficients (Table S1). This approach has been previously shown to yield good agreement with experimental data for $\mathrm{Ba}_{8} \mathrm{Ga}_{16} \mathrm{Ge}_{30}{ }^{26}$ The band gaps for all compositions were individually corrected by using a rigid ("scissors") shift. In particular, each of these was set equal to the value obtained by performing DFT calculations for the same structure using the $\mathrm{mBJ}$ functional, which gives band gaps in better agreement with experiment. ${ }^{42,43}$ Still, our tests reveal that this correction leaves the electrical conductivity largely unaffected, while the Seebeck coefficient is only slightly enhanced at temperatures above $700 \mathrm{~K}$ (see Figure S7 and Supporting Information Note S5).

\section{RESULTS}

Evidence for an Order-Disorder Transition. The hallmark for an order-disorder transformation as a continuous order phase transition is the existence of a discontinuity in a property that corresponds to the second derivative of the free energy and is therefore reflected by a sharp ( $\lambda$-shaped) feature in the heat capacity. ${ }^{44}$ Since the critical slowdown in the vicinity of the phase transition limits the efficiency of standard MC simulations, here, we employ the WL method. ${ }^{32}$ Specifically, all results presented and discussed in this subsection were obtained from calculations based on $2 \times 2$ $\times 2 \mathrm{Ba}_{8} \mathrm{Al}_{x} \mathrm{Ga}_{16-x} \mathrm{Ge}_{30}$ supercells.

Remarkably, both the experimentally measured heat capacity and the calculated contribution from order-disorder display a distinct peak at a specific temperature $T_{\text {trans, }}$, providing strong evidence for the existence of a continuous-order phase transition (Figure 1b,c). Another corroborating piece of evidence is the significant difference in the heat capacity 
above and below $T_{\text {trans }}$. This behavior is observed to varying degree for all compositions considered in this study (Figure 1d) and visible in transition temperature, peak height, and magnitude of the jump (Figure S4). The change in order that underlies this phase transition is directly apparent from the $\mathrm{Al}$ and Ga SOFs, which change substantially around $T_{\text {trans }}$ (see Figure 1e,f, Figure S1, and Supporting Information Note S1).

While the results from both experiments and calculations agree qualitatively, the theoretical estimates of the transition temperature and the magnitude of the jumps in the heat capacity are notably lower than the experimental values (see Figure S4 and Supporting Information Note S4). It must be emphasized that the energy differences involved in this type of transition are extremely small. As a result, small errors that inevitably enter, for example, via the exchange-correlation functional or the CE model, lead to notable errors in the description of the transition temperature and by correlation the magnitude of the change in the heat capacity. In addition, the structural transformation may lead to changes in the contribution to the total heat capacity from sources other than disorder (see Figure S8 and Supporting Information Note S6). The simulations, however, agree qualitatively with the feature in the heat capacity and agree quantitatively with measurements of the SOFs (also see refs 23 and 26), providing microscopic insight into the origin of this transition.

Implications for Electronic Transport. While the existence of an order-disorder transition in inorganic clathrates is interesting in its own right, we now show that it has a direct impact on materials properties, crucially the electronic transport coefficients, which determine the thermoelectric performance. Here, we focus on the electrical conductivity $\sigma$ and the Seebeck coefficient $S$. We have used BTT to predict the temperature dependence of the two former properties for three different compositions, namely, $\mathrm{Ba}_{8} \mathrm{Ga}_{16} \mathrm{Ge}_{30}, \mathrm{Ba}_{8} \mathrm{Al}_{5} \mathrm{Ga}_{11} \mathrm{Ge}_{30}$, and $\mathrm{Ba}_{8} \mathrm{Al}_{16} \mathrm{Ge}_{30}$ (Figure 2).

Our calculations show that better agreement with the experiment is achieved when the order-disorder transition is taken into account since the data for the HT configurations match the measurements better above $700 \mathrm{~K}$ (Figure $2 \mathrm{~b}, \mathrm{~d}, \mathrm{e}$ ). Interestingly, the slope of the Seebeck coefficient increases rather sharply at a specific temperature for all three compositions (Figure $2 \mathrm{~d}-\mathrm{f}$ ). Even so, it is only $\mathrm{Ba}_{8} \mathrm{Al}_{16} \mathrm{Ge}_{30}$ that exhibits a distinct feature, in the form of a bulge, in the measured electrical conductivity at about the same point (Figure 2c). We note that perfect agreement cannot be expected since the HT structure was extracted at an arbitrarily chosen temperature of $1200 \mathrm{~K}$. It is moreover important to keep in mind that the GS is practically unattainable in the experiments because the configuration freezes in at an elevated temperature as discussed previously. ${ }^{23}$ One should also stress that it is only the band gaps that have been set to match values obtained with the $\mathrm{mBJ}$ potential. While the shape of the bands as well as the dispersion can thus be expected to be less accurate, a visual comparison indicates that the differences are in fact very small, as was also concluded in an earlier study. ${ }^{26}$

Insight from the Band Structure. The effect of the order-disorder transition on the transport properties described above can be related to a change in the underlying electronic structure. Our calculations clearly indicate that the transformation from the ordered state to the disordered state leads to significant changes in the band structure (Figure 3). It is moreover evident that this effect is the most pronounced in the case of $\mathrm{Ba}_{8} \mathrm{Ga}_{16} \mathrm{Ge}_{30}$, slightly less so in $\mathrm{Ba}_{8} \mathrm{Al}_{5} \mathrm{Ga}_{11} \mathrm{Ge}_{30}$, and

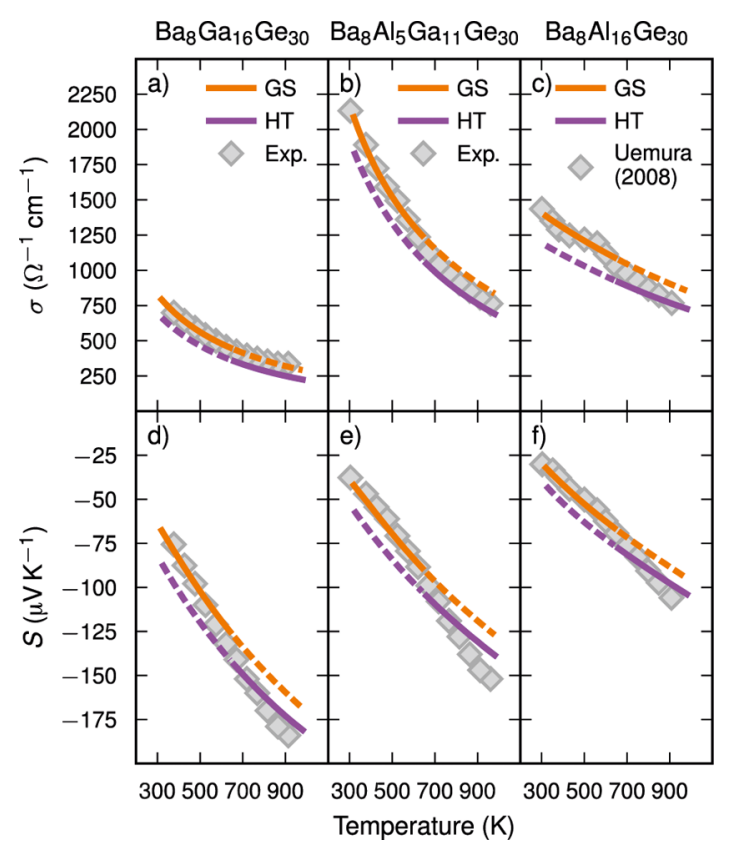

Figure 2. $(a-c)$ Electrical conductivity and $(d-f)$ Seebeck coefficient as a function of temperature. The calculated results for the GS and HT structures have been plotted as orange and purple lines, respectively, while the gray diamonds represent data from experiments. The former curves correspond to the doping level that gave the best agreement between the measurements and calculated Seebeck coefficient for the GS up to $650 \mathrm{~K}$. In addition, the experimental electrical conductivity was used to fit the relaxation time, given by the expression $\tau_{\text {eff }}=\tau_{300 \mathrm{~K}}(300 \mathrm{~K} / \mathrm{T})^{a}$, in the same temperature interval. Note that the experimental measurements for $\mathrm{Ba}_{8} \mathrm{Al}_{5} \mathrm{Ga}_{11} \mathrm{Ge}_{30}$ have been performed on a single crystal, while the data for $\mathrm{Ba}_{8} \mathrm{Ga}_{16} \mathrm{Ge}_{30}$ and $\mathrm{Ba}_{8} \mathrm{Al}_{16} \mathrm{Ge}_{30}$ correspond to polycrystalline samples, of which the latter stems from a study by Uemura et al. ${ }^{45}$

relatively small for $\mathrm{Ba}_{8} \mathrm{Al}_{16} \mathrm{Ge}_{30}$. Specifically, the band gap shrinks in all three cases, but the magnitude of the change decreases with $x$. In terms of the transport properties, it can be shown that energies close to the Fermi level at $700 \mathrm{~K}, \varepsilon_{\mathrm{F}}^{700 \mathrm{~K}}$, and $\varepsilon_{\mathrm{F}}^{700 \mathrm{~K}} \pm 2 k_{\mathrm{B}} T$ provide the largest contributions to the electrical conductivity and the Seebeck coefficient, respectively (see Figure S5 and Supporting Information Note S5, ${ }^{46}$ ). Our calculations reveal that the electronic density of states (DOS) for the HT configuration is enhanced for $\varepsilon \approx \varepsilon_{\mathrm{F}}^{700 \mathrm{~K}}+2 k_{\mathrm{B}} T$ in the case of $\mathrm{Ba}_{8} \mathrm{Ga}_{16} \mathrm{Ge}_{30}$ and $\mathrm{Ba}_{8} \mathrm{Al}_{5} \mathrm{Ga}_{11} \mathrm{Ge}_{30}$, which explains the increase in the Seebeck coefficient. While there is a similar trend for $\mathrm{Ba}_{8} \mathrm{Al}_{16} \mathrm{Ge}_{30}$, it appears at higher energies (Figure $3 \mathrm{a}, \mathrm{d}, \mathrm{g})$. In this case, the DOS is also larger than that in the GS around $\varepsilon_{\mathrm{F}}^{700 \mathrm{~K}}$, which should lead to an enhancement of the electrical conductivity.

The previously described observations agree fairly well with the predictions obtained within BTT; for instance, the change in the electrical conductivity induced by the order-disorder transition is indeed found to be larger for $\mathrm{Ba}_{8} \mathrm{Al}_{16} \mathrm{Ge}_{30}$. Based on the above arguments, it appears, however, that there is a discrepancy with respect to the absolute value of the Seebeck coefficient, which according to the transport calculations should increase for all three systems. Part of the explanation is that we have so far only compared the DOS and, hence, neglected the fact that it is actually the electron group velocities, which correspond to the slopes of the bands $\nabla_{k} \varepsilon$, that determine the electronic transport properties. A closer inspection of the band structure reveals that the region around 

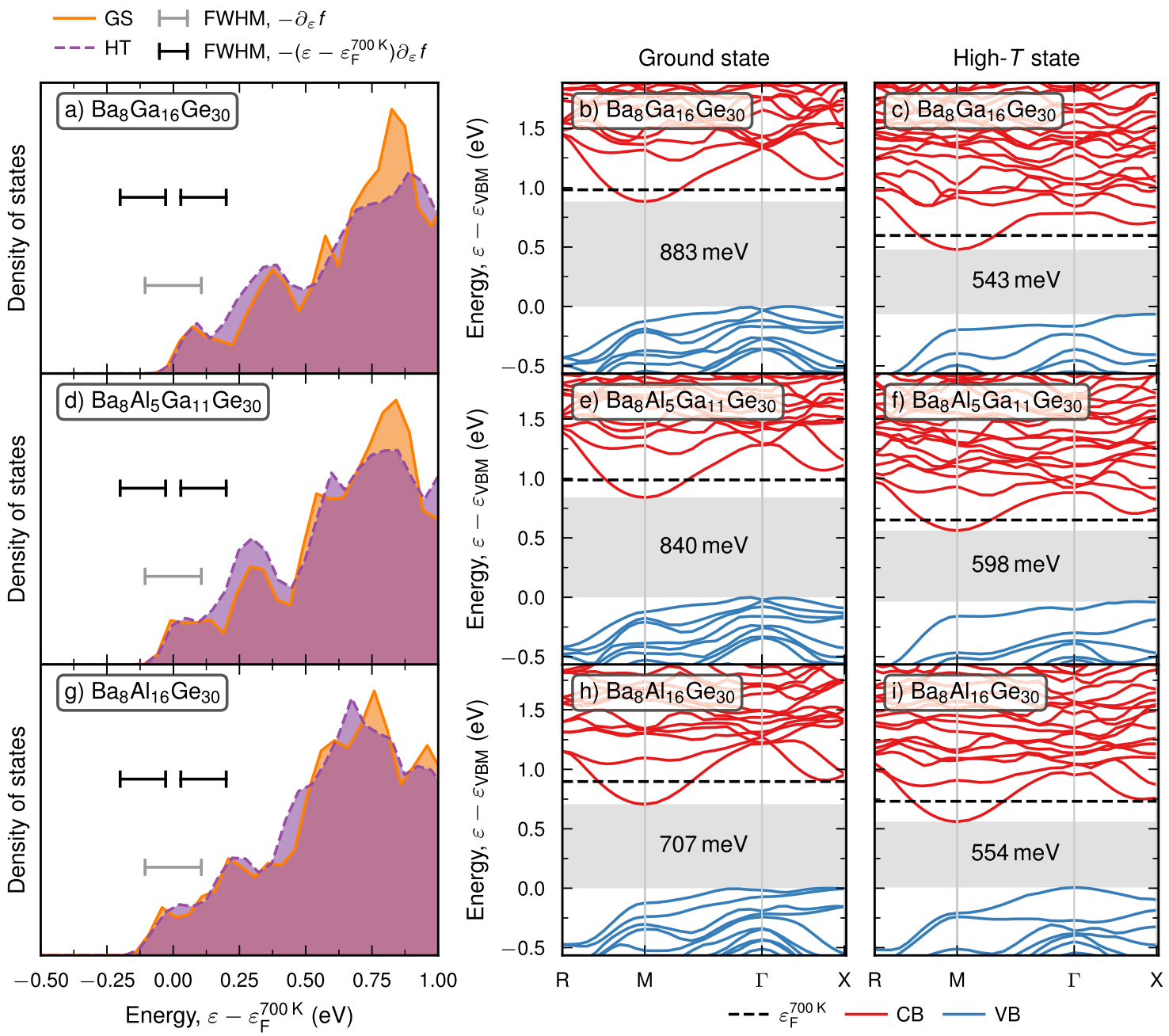

Figure 3. Electronic DOSs as well as band structures for $(\mathrm{a}-\mathrm{c}) \mathrm{Ba}_{8} \mathrm{Ga}_{16} \mathrm{Ge}_{30},(\mathrm{~d}-\mathrm{f}) \mathrm{Ba}_{8} \mathrm{Al}_{5} \mathrm{Ga}_{11} \mathrm{Ge}_{30}$, and $(\mathrm{g}-\mathrm{i}) \mathrm{Ba}_{8} \mathrm{Al}_{16} \mathrm{Ge}_{30}$. In (a,d,g), the DOSs for the GS and HT structures are represented by purple dotted and orange solid curves, respectively. The bands, meanwhile, have been plotted in separate panels for the former $(b, e, h)$ and latter $(c, f, i)$ states, where the filled gray areas correspond to the band gaps. Moreover, the full width at half-maximum (fwhm) for both the derivative of the Fermi distribution function, $-\partial_{\varepsilon} f$ (gray horizontal bar), and the two peaks featured by the product $-\left(\varepsilon-\varepsilon_{\mathrm{F}}^{700 \mathrm{~K}}\right)^{\alpha} \partial_{\varepsilon} f$ (black horizontal bars) has been indicated in $(\mathrm{a}, \mathrm{d}, \mathrm{g})$. Here, $\varepsilon_{\mathrm{F}}^{700 \mathrm{~K}}$ is the doping level that provides the best agreement between the calculated and experimental Seebeck coefficients at $700 \mathrm{~K}$. For each composition, the energy scales have been aligned using the Ba $1 \mathrm{~s}$ states, with the GS valance band (VB) maximum set to 0 , using the procedure described in ref 47 .

the conduction band minimum (CBM), which is located at the $M$-point, appears to be very similar for both the HT configuration and the GS, even though it lies closer to the valence band maximum (VBM) in the former case (Figure $3 \mathrm{~b}, \mathrm{c}, \mathrm{e}, \mathrm{f}, \mathrm{h}, \mathrm{i})$. While the valence band is transformed to a larger degree, these are unimportant for the relevant doping levels since they correspond to energies much lower than $\varepsilon_{\mathrm{F}}^{700 \mathrm{~K}}-$ $2 k_{\mathrm{B}} T$. Instead, the most significant change is the downward shift of the bands at the $\Gamma$-point, which brings additional states into the window around $\varepsilon_{\mathrm{F}}^{700 \mathrm{~K}}+2 k_{\mathrm{B}} T$. At the same time, the bands flatten, which leads to lower group velocities. The fact that the latter effect is the most pronounced for $\mathrm{Ba}_{8} \mathrm{Ga}_{16} \mathrm{Ge}_{30}$ and the least for $\mathrm{Ba}_{8} \mathrm{Al}_{16} \mathrm{Ge}_{30}$ can be one reason why the increase in the magnitude of the Seebeck coefficient is comparable for $\mathrm{Ba}_{8} \mathrm{Ga}_{16} \mathrm{Ge}_{30}, \mathrm{Ba}_{8} \mathrm{Al}_{5} \mathrm{Ga}_{11} \mathrm{Ge}_{30}$, and $\mathrm{Ba}_{8} \mathrm{Al}_{16} \mathrm{Ge}_{30}$ in spite of the smaller DOS enhancement observed for the latter composition.

\section{DISCUSSION}

Although several previous studies have reported anomalies in the HT measurements for inorganic type I clathrates, these have, until now, not been related to a transformation between an ordered state and a disordered state. Here, we have reported convincing evidence that $\mathrm{Ba}_{8} \mathrm{Al}_{x} \mathrm{Ga}_{16-x} \mathrm{Ge}_{30}$ undergoes such a transition and that this has a direct effect on the band structure and electronic transport properties. Additional calculations, which will be detailed in a separate article, as well as earlier studies of $\mathrm{Ba}_{8} \mathrm{Al}_{16} \mathrm{Si}_{30}{ }^{23,24}$ show that this phenomenon is also present in silicon-based systems, namely, $\mathrm{Ba}_{8} \mathrm{Ga}_{16} \mathrm{Si}_{30}$ and $\mathrm{Ba}_{8} \mathrm{Al}_{16} \mathrm{Si}_{30}$, indicating that it is a common feature of inorganic type I clathrates.

The existence of an order-disorder transition has important implications with regard to both future studies and the interpretation of existing data. Specifically, one can conclude the following:

i The jump in the heat capacity implies that using the Dulong-Petit limit or assuming that the value remains constant above room temperature, which is relatively common, ${ }^{8,48-50}$ can lead to an underestimation of the thermal conductivity and, hence, an overestimation of the thermoelectric performance. ${ }^{11}$ As emphasized in a 
recent review by Agne et al., ${ }^{12}$ the significance of phase transitions is often neglected when determining the thermal transport properties of thermoelectric materials. This has already been demonstrated for copper chalcogenides, where this effect can explain the extraordinarily high $z T$ values that had been reported earlier. $^{14,51}$

ii Any transport calculation that is based on a single structure, especially the GS, is likely to underestimate the Seebeck coefficient. In other words, the previously reported predictions of the maximum efficiency at an optimized doping level ${ }^{45,52}$ are most likely lower than what could be achieved in reality, provided the corresponding carrier concentrations are attainable.

iii Due to the temperature and composition dependence of the transformation, it should be possible to achieve temperature-dependent band-structure engineering. For instance, it could potentially enhance or facilitate the application of the modulation ${ }^{53-55}$ and temperaturedependent $^{56,57}$ doping concepts or even help combine the two.

iv When subjected to a temperature gradient, for instance, as part of a thermoelectric module, the sections of the leg for which $T<T_{\mathrm{c}}$ and $T \geq T_{\mathrm{c}}$ will be in the ordered and disordered states, respectively, which effectively gives rise to an intrinsic functional gradient. If properly tuned, this could potentially lead to an enhanced overall efficiency. Whether or not this can be achieved in practice, however, remains to be seen.

$\mathrm{v}$ The existence of a phase transition may also be of importance with regard to the structural and thermal stability of clathrate phases. In particular, it is likely that this has a bearing on the decomposition behavior recently reported by Reardon et al. ${ }^{5}$ Indeed, the fact that the SOFs change dramatically at around $650 \mathrm{~K}$ in $\mathrm{Ba}_{8} \mathrm{Ga}_{16} \mathrm{Ge}_{30}$ indicates that there exists not only a driving force for the redistribution of the host atoms but also enough kinetic energy to surmount the associated energy barriers. It should be stressed that further studies are required that address the stability of clathrates under different conditions, for instance, when these are heated above, or subjected to temperature gradients that span, the transition point.

Another key insight gained from this study is that quaternary clathrate systems allow one to optimize the band structure for an optimal carrier concentration by adjusting the composition. In the case of $\mathrm{Ba}_{8} \mathrm{Al}_{x} \mathrm{Ga}_{y} \mathrm{Ge}_{46-x-y}$, this corresponds to varying the ratio between $\mathrm{Al}$ and $\mathrm{Ga}$ while keeping the number of $\mathrm{Ge}$ atoms fixed. Our results furthermore suggest that both the temperature at which the transformation takes place and the effect it has on the band structure, and therefore the transport properties, vary with $\mathrm{Al}$ content. While $\mathrm{Ba}_{8} \mathrm{Al}_{x} \mathrm{Ga}_{y} \mathrm{Ge}_{46-x-y}$ might not be the best candidate for further optimization, due to its cost, it is more than plausible that the same ideas can be applied to systems that are made up of more abundant elements, such as $\mathrm{Ba}_{8} \mathrm{Al}_{x} \mathrm{Ga}_{y} \mathrm{Si}_{46-x-y}$. More precisely, the calculations presented in this study together with the existing experimental evidence ${ }^{58,59}$ indicate that it should be possible to identify an $\mathrm{Al} / \mathrm{Ga}$ ratio that gives a maximum efficiency, which could be further enhanced if the modulation doping concept was also employed.
From a more general perspective, the connection between chemical order and transport properties revealed here in the case of an inorganic clathrate is likely to be a more general occurrence in materials that exhibit some form of chemical ordering. In fact, there exist several studies that have shown the importance of transformations between states with ordered and disordered vacancies or at least considered their existence in functional materials such as $\mathrm{Li}_{x} \mathrm{CoO}_{2},{ }^{60} \mathrm{Zn}_{5} \mathrm{Sb}_{4} \mathrm{In}_{2-\delta}$, ${ }^{15}$ zinc antimonides, ${ }^{12,61} \mathrm{ZnAl}_{2} \mathrm{O}_{4}{ }^{62} \mathrm{Mg}_{3}(\mathrm{Bi}, \mathrm{Sb})_{2},{ }^{63} \mathrm{AgCrSe}_{2}{ }^{64}$ $\mathrm{Ag}_{8} \mathrm{SiSe}_{6}{ }^{65}(\mathrm{Tm}, \mathrm{Y})(\mathrm{Ag}, \mathrm{Cu}) \mathrm{Te}_{2},{ }^{66} \mathrm{Cu}_{2-x} \mathrm{Se}^{14,67} \mathrm{Cu}_{7} \mathrm{PSe}_{6}{ }^{68}$ $\mathrm{Cu}_{7} \mathrm{PSe}_{6-x} \mathrm{~S}_{x}{ }^{13} \mathrm{GeTe}^{69}$ half-Heuslers, ${ }^{70,71}$ and partially filled skutterudites. $^{72}$ It appears more than likely that similar phenomena should be observed in other vacancy-containing compounds with complex unit cells, for instance $\mathrm{K}_{2.5} \mathrm{Bi}_{8.5} \mathrm{Se}_{14}{ }^{73}$ $\mathrm{K}_{2} \mathrm{Bi}_{8} \mathrm{Se}_{13}{ }^{74}$ and $(\mathrm{Yb}, \mathrm{Eu}, \mathrm{Ca}, \mathrm{Sr})_{9}(\mathrm{Mn}, \mathrm{Zn}, \mathrm{Cd})_{4+x}(\mathrm{Sb}, \mathrm{Bi})_{9} \cdot{ }^{75,76}$ Quite a few investigations of order-disorder transitions for systems with mixed occupancies have also been reported, which include $\mathrm{Cu}_{2}(\mathrm{Zn}, \mathrm{Cd}, \mathrm{Hg})(\mathrm{Si}, \mathrm{Ge}, \mathrm{Sn}) \mathrm{Te}_{4}{ }^{77}$ and II-IV-$\mathrm{V}_{2}{ }^{78}$ semiconductors, $\mathrm{Cu}_{2} \mathrm{SnS}_{3},{ }^{79} \mathrm{Cu}_{2} \mathrm{ZnSn}(\mathrm{S}, \mathrm{Se})_{4}{ }^{80}$ LAST alloys, ${ }^{81}$ and perovskite oxynitrides. ${ }^{82}$ Based on our study, we expect that the same holds true for other alloys, which include "unconventional" superconductors, ${ }^{83}$ nitride semiconductors, ${ }^{84}$ inverse $^{85}$ and full $^{86}$ Heuslers, chalcogenides, ${ }^{87-89}$ pavonites, ${ }^{90,91}$ pnictides, $^{92-94}$ phosphides, ${ }^{95}$ oxides, $^{96,97}$ and Chevrel $^{98,99}$ and Zintl ${ }^{100-102}$ phases.

\section{CONCLUSIONS}

In this paper, we have presented a compelling proof in the form of both experimental and calculated data that the inorganic type I clathrates $\mathrm{Ba}_{8} \mathrm{Al}_{x} \mathrm{Ga}_{16-x} \mathrm{Ge}_{30}$, with $0 \leq x \leq 16$, exhibit an order-disorder transition, which, moreover, has a direct and significant effect on the thermoelectric properties. Even though the transition temperature and the magnitude of the associated jump in the heat capacity predicted from simulations are notably lower than the measured values, combining the calculated transport properties for the GS and a representative HT configuration leads to near quantitative agreement with experiments. Furthermore, we have been able to relate the shifts in both the Seebeck coefficient and electrical conductivity to changes in the band structure induced by the transformation. We believe that this insight not only signifies a significant step toward understanding the intricate relationship between chemical ordering and physical properties of inorganic clathrates but also opens up new routes for achieving high thermoelectric efficiencies and, thereby, brings this group of materials closer to being viable for commercial applications. In a more general sense, relationships between ordering and transport such as the one uncovered here are likely to be present in related materials including other thermoelectrics. Finally, the success of this study can be seen as a proof of the great advances that can be achieved by conducting experimental and computational investigations in tandem.

\section{ASSOCIATED CONTENT}

\section{SI Supporting Information}

The Supporting Information is available free of charge at https://pubs.acs.org/doi/10.1021/acs.chemmater.1c00731.

SOFs versus temperature and $\mathrm{Al}$ content, measured heat capacity and heat flow, size dependence of the transition temperature, jump in heat capacity and transition temperature, Fermi distribution function, Seebeck coefficients for representative and average CV structures, 
transport calculations with $\mathrm{mBJ}$ and vdW-DF-CX band gaps, electronic contribution to heat capacity, fit parameters for transport calculations, temperature and composition dependence of SOFs, measured heat capacity and heat flow, size dependence of transition temperature, jump in heat capacity and transition temperature, transport calculations, and electronic heat capacity (PDF)

\section{AUTHOR INFORMATION}

\section{Corresponding Author}

Paul Erhart - Department of Physics, Chalmers University of Technology, Gothenburg 41296, Sweden; 이이이.org/00000002-2516-6061; Email: erhart@chalmers.se

\section{Authors}

Joakim Brorsson - Department of Chemistry and Chemical Engineering, Chalmers University of Technology, Gothenburg 41296, Sweden

Yifei Zhang - Department of Chemistry and Chemical Engineering, Chalmers University of Technology, Gothenburg 41296, Sweden

Anders E. C. Palmqvist - Department of Chemistry and Chemical Engineering, Chalmers University of Technology, Gothenburg 41296, Sweden; (1) orcid.org/0000-0002-75793936

Complete contact information is available at:

https://pubs.acs.org/10.1021/acs.chemmater.1c00731

\section{Notes}

The authors declare no competing financial interest.

\section{ACKNOWLEDGMENTS}

This work was funded by the Knut and Alice Wallenberg Foundation (2014.0226), the Swedish Research Council (2018-06482 and 2020-04935), the Swedish Foundation for Strategic Research (SSF) through the Swedish national graduate school in neutron scattering (SwedNess), and the Danish Council for Strategic Research via the Programme Commission on Sustainable Energy and Environment through sponsoring of the project "CTEC-Center for Thermoelectric Energy Conversion” (project no. 1305-00002B). The computations were enabled by resources provided by the Swedish National Infrastructure for Computing (SNIC) at NSC, C3SE, and PDC partially funded by the Swedish Research Council through grant agreement no. 2018-05973.

\section{REFERENCES}

(1) Christensen, M.; Johnsen, S.; Iversen, B. B. Thermoelectric clathrates of type I. Dalton Trans. 2010, 39, 978-992.

(2) Takabatake, T.; Suekuni, K.; Nakayama, T.; Kaneshita, E. Phonon-glass electron-crystal thermoelectric clathrates: Experiments and theory. Rev. Mod. Phys. 2014, 86, 669-716.

(3) Dolyniuk, J.-A.; Owens-Baird, B.; Wang, J.; Zaikina, J. V.; Kovnir, K. Clathrate thermoelectrics. Mater. Sci. Eng., R 2016, 108, 1-46.

(4) Slack, G. A. In CRC Handbook of Thermoelectrics; Rowe, D. M., Ed.; CRC Press: Boca Raton, USA, 1995; Chapter 34, pp 407-440. (5) Reardon, H.; Blichfeld, A. B.; Kasai, H.; Yin, H.; Bøjesen, E. D.; Iversen, B. B. Revealing the slow decomposition kinetics of type-I clathrate $\mathrm{Ba}_{8} \mathrm{Ga}_{16} \mathrm{Ge}_{30}$. Phys. Chem. Chem. Phys. 2017, 19, 1573415744.

(6) Kuznetsov, V. L.; Kuznetsova, L. A.; Kaliazin, A. E.; Rowe, D. M. Preparation and thermoelectric properties of $\mathrm{A}_{8}{ }^{\mathrm{II}} \mathrm{B}_{16}{ }_{16}{ }^{\mathrm{II}} \mathrm{B}_{30}{ }^{\mathrm{IV}}$ clathrate compounds. J. Appl. Phys. 2000, 87, 7871-7875.
(7) Saramat, A.; Svensson, G.; Palmqvist, A. E. C.; Stiewe, C.; Mueller, E.; Platzek, D.; Williams, S. G. K.; Rowe, D. M.; Bryan, J. D.; Stucky, G. D. Large thermoelectric figure of merit at high temperature in Czochralski-grown clathrate $\mathrm{Ba}_{8} \mathrm{Ga}_{16} \mathrm{Ge}_{30}$. J. Appl. Phys. 2006, 99, 023708 .

(8) Okamoto, N. L.; Kishida, K.; Tanaka, K.; Inui, H. Crystal structure and thermoelectric properties of type-I clathrate compounds in the $\mathrm{Ba}-\mathrm{Ga}-\mathrm{Ge}$ system. J. Appl. Phys. 2006, 100, 073504.

(9) Toberer, E. S.; Christensen, M.; Iversen, B. B.; Snyder, G. J. High temperature thermoelectric efficiency in $\mathrm{Ba}_{8} \mathrm{Ga}_{16} \mathrm{Ge}_{30}$. Phys. Rev. B: Condens. Matter Mater. Phys. 2008, 77, 075203.

(10) Martin, J.; Wang, H.; Nolas, G. S. Optimization of the thermoelectric properties of $\mathrm{Ba}_{8} \mathrm{Ga}_{16} \mathrm{Ge}_{30}$. Appl. Phys. Lett. 2008, 92, 222110.

(11) May, A. F.; Toberer, E. S.; Saramat, A.; Snyder, G. J. Characterization and analysis of thermoelectric transport in $n$-type $\mathrm{Ba}_{8} \mathrm{Ga}_{x} \mathrm{Ge}_{30-x}$. Phys. Rev. B: Condens. Matter Mater. Phys. 2009, 80, 125205.

(12) Agne, M. T.; Voorhees, P. W.; Snyder, G. J. Phase Transformation Contributions to Heat Capacity and Impact on Thermal Diffusivity, Thermal Conductivity, and Thermoelectric Performance. Adv. Mater. 2019, 31, 1902980.

(13) Reissig, F.; Heep, B.; Panthöfer, M.; Wood, M.; Anand, S.; Snyder, G. J.; Tremel, W. Effect of anion substitution on the structural and transport properties of argyrodites $\mathrm{Cu}_{7} \mathrm{PSe}_{6-x} S_{x^{*}}$. Dalton Trans. 2019, 48, 15822-15829.

(14) Brown, D. R.; Heijl, R.; Borup, K. A.; Iversen, B. B.; Palmqvist, A.; Snyder, G. J. Relating phase transition heat capacity to thermal conductivity and effusivity in $\mathrm{Cu}_{2} \mathrm{Se}$. Phys. Status Solidi RRL 2016, 10, 618-621.

(15) Wu, Y.; Litvinchuk, A. P.; Toberer, E. S.; Snyder, G. J.; Newman, N.; Fischer, A.; Scheidt, E.-W.; Scherer, W.; Häussermann, $\mathrm{U}$. Thermoelectric properties of $\mathrm{Zn}_{5} \mathrm{Sb}_{4} \mathrm{In}_{2-\delta}(\delta=0.15)$. J. Appl. Phys. 2012, 111, 123712.

(16) Condron, C. L.; Kauzlarich, S. M.; Gascoin, F.; Snyder, G. J. Thermoelectric Properties and Microstructure of $\mathrm{Ba}_{8} \mathrm{Al}_{14} \mathrm{Si}_{31}$ and $\mathrm{EuBa}_{7} \mathrm{Al}_{13} \mathrm{Si}_{33}$. Chem. Mater. 2006, 18, 4939-4945.

(17) Tsujii, N.; Roudebush, J. H.; Zevalkink, A.; Cox-Uvarov, C. A.; Jeffery Snyder, G.; Kauzlarich, S. M. Phase stability and chemical composition dependence of the thermoelectric properties of the typeI clathrate $\mathrm{Ba}_{8} \mathrm{Al}_{x} \mathrm{Si}_{46-x},(8 \leq x \leq 15)$. J. Solid State Chem. 2011, 184, 1293-1303.

(18) Condron, C. L.; Kauzlarich, S. M.; Ikeda, T.; Snyder, G. J.; Haarmann, F.; Jeglič, P. Synthesis, Structure, and High-Temperature Thermoelectric Properties of Boron-Doped $\mathrm{Ba}_{8} \mathrm{Al}_{14} \mathrm{Si}_{31}$ Clathrate I Phases. Inorg. Chem. 2008, 47, 8204-8212.

(19) Roudebush, J. H.; Toberer, E. S.; Hope, H.; Jeffrey Snyder, G.; Kauzlarich, S. M. Crystal structure, characterization and thermoelectric properties of the type-I clathrate $\mathrm{Ba}_{8-y} \mathrm{Sr}_{y} \mathrm{Al}_{14} \mathrm{Si}_{32}(0.6 \leq y \leq$ 1.3) prepared by aluminum flux. J. Solid State Chem. 2011, 184, $1176-1185$

(20) Okamoto, N. L.; Kishida, K.; Tanaka, K.; Inui, H. Effect of In additions on the thermoelectric properties of the type-I clathrate compound $\mathrm{Ba}_{8} \mathrm{Ga}_{16} \mathrm{Ge}_{30}$. J. Appl. Phys. 2007, 101, 113525.

(21) Christensen, S.; Bjerg, L.; Kaltzoglou, A.; Juranyi, F.; Fässler, T.; Unruh, T.; Christensen, M. Guest host interaction and low energy host structure dynamics in tin clathrates. J. Appl. Phys. 2013, 113, 084902.

(22) Kaltzoglou, A.; Fässler, T.; Christensen, M.; Johnsen, S.; Iversen, B.; Presniakov, I.; Sobolev, A.; Shevelkov, A. Effects of the order-disorder phase transition on the physical properties of $\mathrm{A}_{8} \mathrm{Sn}_{44} \square_{2}$ (A = Rb, Cs). J. Mater. Chem. 2008, 18, 5630-5637.

(23) Ångqvist, M.; Erhart, P. Understanding chemical ordering in intermetallic clathrates from atomic scale simulations. Chem. Mater. 2017, 29, 7554.

(24) Troppenz, M.; Rigamonti, S.; Sofo, J. O.; Draxl, C. Partial Order-Disorder Transition Driving Closure of Band Gap: Example of Thermoelectric Clathrates. Science 2020, eprint arXiv:2009.11137. 
(25) For a general type-I ternary clathrate, $\mathrm{A}_{8} \mathrm{~B}_{x} \mathrm{C}_{46-x}$, with $x=16$ there are $46 ! /(30 ! 16 !) \approx 10^{12}$ ways to select the 16 sites occupied by the $\mathrm{B}$ atoms, which is reduced by about a factor of 10 if symmetry is taken into account.

(26) Ångqvist, M.; Lindroth, D. O.; Erhart, P. Optimization of the thermoelectric power factor: Coupling between chemical order and transport properties. Chem. Mater. 2016, 28, 6877.

(27) Troppenz, M.; Rigamonti, S.; Draxl, C. Predicting GroundState Configurations and Electronic Properties of the Thermoelectric Clathrates $\mathrm{Ba}_{8} \mathrm{Al}_{x} \mathrm{Si}_{46-x}$ and $\mathrm{Sr}_{8} \mathrm{Al}_{x} \mathrm{Si}_{46-x}$. Chem. Mater. 2017, 29, 2414-2424.

(28) Christensen, M.; Iversen, B. B. Host Structure Engineering in Thermoelectric Clathrates. Chem. Mater. 2007, 19, 4896-4905.

(29) Heat capacity determination at high temperatures by TGA/DSC Part 1: DSC standard procedures; METTLER TOLEDO Thermal Analysis UserCom 2010, Vol. 27, pp 1-4.

(30) Ångqvist, M.; Muñoz, W. A.; Rahm, J. M.; Fransson, E.; Durniak, C.; Rozyczko, P.; Rod, T. H.; Erhart, P. ICET-A Python Library for Constructing and Sampling Alloy Cluster Expansions. Adv. Theory Simul. 2019, 2, 1900015.

(31) Fransson, E.; Eriksson, F.; Erhart, P. Efficient construction of linear models in materials modeling and applications to force constant expansions. npj Comput. Mater. 2020, 6, 135.

(32) Wang, F.; Landau, D. P. Efficient, Multiple-Range Random Walk Algorithm to Calculate the Density of States. Phys. Rev. Lett. 2001, 86, 2050-2053.

(33) Kresse, G.; Furthmüller, J. Efficient iterative schemes for ab initio total-energy calculations using a plane-wave basis set. Phys. Rev. B: Condens. Matter Mater. Phys. 1996, 54, 11169.

(34) Blöchl, P. E. Projector augmented-wave method. Phys. Rev. B: Condens. Matter Mater. Phys. 1994, 50, 17953-17979.

(35) Kresse, G.; Joubert, D. From ultrasoft pseudopotentials to the projector augmented-wave method. Phys. Rev. B: Condens. Matter Mater. Phys. 1999, 59, 1758-1775.

(36) Berland, K.; Cooper, V. R.; Lee, K.; Schröder, E.; Thonhauser, T.; Hyldgaard, P.; Lundqvist, B. I. Van Der Waals Forces in Density Functional Theory: A Review of the vdW-DF Method. Rep. Prog. Phys. 2015, 78, 066501.

(37) Berland, K.; Hyldgaard, P. Exchange functional that tests the robustness of the plasmon description of the van der Waals density functional. Phys. Rev. B: Condens. Matter Mater. Phys. 2014, 89, 035412 .

(38) van de Walle, A.; Tiwary, P.; de Jong, M.; Olmsted, D. L.; Asta, M.; Dick, A.; Shin, D.; Wang, Y.; Chen, L.-Q.; Liu, Z.-K. Efficient stochastic generation of special quasirandom structures. Calphad 2013, 42, 13.

(39) Becke, A. D.; Johnson, E. R. A simple effective potential for exchange. J. Chem. Phys. 2006, 124, 221101.

(40) Tran, F.; Blaha, P. Accurate Band Gaps of Semiconductors and Insulators with a Semilocal Exchange-Correlation Potential. Phys. Rev. Lett. 2009, 102, 226401.

(41) Madsen, G. K. H.; Carrete, J.; Verstraete, M. J. BoltzTraP2, a program for interpolating band structures and calculating semiclassical transport coefficients. Comput. Phys. Commun. 2018, 231, $140-145$.

(42) Chen, W.; Pöhls, J.-H.; Hautier, G.; Broberg, D.; Bajaj, S.; Aydemir, U.; Gibbs, Z. M.; Zhu, H.; Asta, M.; Snyder, G. J.; Meredig, B.; White, M. A.; Persson, K.; Jain, A. Understanding thermoelectric properties from high-throughput calculations: trends, insights, and comparisons with experiment. J. Mater. Chem. C 2016, 4, 4414-4426.

(43) Kutepov, A. L.; Ruth, A. Electronic structure and thermoelectric properties of $\mathrm{CoAsSb}$ with post-DFT approaches. Appl. Phys. A: Mater. Sci. Process. 2020, 126, 137.

(44) Pelton, A. D. Phase Diagrams and Thermodynamic Modeling of Solutions; Elsevier, 2019, pp 159-164.

(45) Uemura, T.; Akai, K.; Koga, K.; Tanaka, T.; Kurisu, H.; Yamamoto, S.; Kishimoto, K.; Koyanagi, T.; Matsuura, M. Electronic structure and thermoelectric properties of clathrate compounds $\mathrm{Ba}_{8} \mathrm{Al}_{x} \mathrm{Ge}_{46-x}$. J. Appl. Phys. 2008, 104, 013702.
(46) Ibach, H.; Lüth, H. Solid-State Physics: An Introduction to Principles of Materials Science; Springer Berlin Heidelberg, 2009, pp 135-158.

(47) Pfeifer, V.; Erhart, P.; Li, S.; Rachut, K.; Morasch, J.; Brötz, J.; Reckers, P.; Mayer, T.; Rühle, S.; Zaban, A.; Mora Seró, I.; Bisquert, J.; Jaegermann, W.; Klein, A. Energy Band Alignment between Anatase and Rutile TiO2. J. Phys. Chem. Lett. 2013, 4, 4182-4187.

(48) Anno, H.; Hokazono, M.; Kawamura, M.; Nagao, J.; Matsubara, $\mathrm{K}$. Thermoelectric properties of $\mathrm{Ba}_{8} \mathrm{Ga}_{x} \mathrm{Ge}_{46-x}$ clathrate compounds. Proceedings ICT'02; Twenty-First International Conference on Thermoelectrics, 2002; Vol. 2002, pp 77-80.

(49) Christensen, M.; Snyder, G.; Iversen, B. Proceedings ICT'0625th International Conference on Thermoelectrics; IEEE, 2006, pp 4043.

(50) Hou, X.; Zhou, Y.; Wang, L.; Zhang, W.; Zhang, W.; Chen, L. Growth and thermoelectric properties of $\mathrm{Ba}_{8} \mathrm{Ga}_{16} \mathrm{Ge}_{30}$ clathrate crystals. J. Alloys Compd. 2009, 482, 544-547.

(51) Kang, S. D.; Danilkin, S. A.; Aydemir, U.; Avdeev, M.; Studer, A.; Snyder, G. J. Apparent critical phenomena in the superionic phase transition of $\mathrm{Cu}_{2-x} \mathrm{Se}$. New J. Phys. 2016, 18, 013024.

(52) Akai, K.; Uemura, T.; Kishimoto, K.; Tanaka, T.; Kurisu, H.; Yamamoto, S.; Koyanagi, T.; Koga, K.; Anno, H.; Matsuura, M. FirstPrinciples Study of Semiconducting Clathrate $\mathrm{Ba}_{8} \mathrm{Al}_{16} \mathrm{Ge}_{30}$. J. Electron. Mater. 2009, 38, 1412-1417.

(53) Zhang, Y.; Brorsson, J.; Qiu, R.; Palmqvist, A. E. C. Enhanced Thermoelectric Performance of $\mathrm{Ba}_{8} \mathrm{Ga}_{16} \mathrm{Ge}_{30}$ Clathrate by Modulation Doping and Improved Carrier Mobility. Adv. Electron. Mater. 2021, 7, 2000782.

(54) Zebarjadi, M.; Joshi, G.; Zhu, G.; Yu, B.; Minnich, A.; Lan, Y.; Wang, X.; Dresselhaus, M.; Ren, Z.; Chen, G. Power Factor Enhancement by Modulation Doping in Bulk Nanocomposites. Nano Lett. 2011, 11, 2225-2230.

(55) Yu, B.; Zebarjadi, M.; Wang, H.; Lukas, K.; Wang, H.; Wang, D.; Opeil, C.; Dresselhaus, M.; Chen, G.; Ren, Z. Enhancement of Thermoelectric Properties by Modulation-Doping in Silicon Germanium Alloy Nanocomposites. Nano Lett. 2012, 12, 2077-2082.

(56) Biswas, K.; He, J.; Blum, I. D.; Wu, C.-I.; Hogan, T. P.; Seidman, D. N.; Dravid, V. P.; Kanatzidis, M. G. High-performance bulk thermoelectrics with all-scale hierarchical architectures. Nature 2012, 489, 414-418.

(57) Yamini, S. A.; Ikeda, T.; Lalonde, A.; Pei, Y.; Dou, S. X.; Snyder, G. J. Rational design of p-type thermoelectric PbTe: temperature dependent sodium solubility. J. Mater. Chem. A 2013, $1,8725-8730$.

(58) Onizuka, Y.; Oka, T.; Osada, T.; Miura, H.; Munetoh, S.; Furukimi, O. Thermoelectric Properties of Ga-Doped $\mathrm{Ba}_{8} \mathrm{Al}_{x} \mathrm{Si}_{46-x}$ Clathrate. J. Electron. Mater. 2014, 43, 2059-2063.

(59) Kikuchi, D.; Tadokoro, J.; Eguchi, T. The High-Temperature Thermoelectric Properties of Polycrystalline $\mathrm{Ba}_{8} \mathrm{Ga}_{x} \mathrm{Al}_{y} \mathrm{Si}_{46-x-y}$ Type-I Clathrates. J. Electron. Mater. 2014, 43, 2141-2144.

(60) Wolverton, C.; Zunger, A. First-principles theory of cation and intercalation ordering in $\mathrm{Li}_{x} \mathrm{CoO}_{2}$. J. Power Sources 1999, 81-82, 680-684.

(61) Pomrehn, G. S.; Toberer, E. S.; Snyder, G. J.; van de Walle, A. Entropic stabilization and retrograde solubility in $\mathrm{Zn}_{4} \mathrm{Sb}_{3}$. Phys. Rev. B: Condens. Matter Mater. Phys. 2011, 83, 094106.

(62) Sommer, S.; Bøjesen, E. D.; Lock, N.; Kasai, H.; Skibsted, J.; Nishibori, E.; Iversen, B. B. Probing the validity of the spinel inversion model: a combined SPXRD, PDF, EXAFS and NMR study of $\mathrm{ZnAl}_{2} \mathrm{O}_{4}$. Dalton Trans. 2020, 49, 13449-13461.

(63) Zhang, J.; Song, L.; Iversen, B. B. Insights into the design of thermoelectric $\mathrm{Mg}_{3} \mathrm{Sb}_{2}$ and its analogs by combining theory and experiment. npj Comput. Mater. 2019, 5, 76.

(64) Li, B.; et al. Liquid-like thermal conduction in intercalated layered crystalline solids. Nat. Mater. 2018, 17, 226-230.

(65) Heep, B. K.; Weldert, K. S.; Krysiak, Y.; Day, T. W.; Zeier, W. G.; Kolb, U.; Snyder, G. J.; Tremel, W. High Electron Mobility and Disorder Induced by Silver Ion Migration Lead to Good Thermo- 
electric Performance in the Argyrodite $\mathrm{Ag}_{8} \mathrm{SiSe}_{6}$. Chem. Mater. 2017, 29, 4833-4839.

(66) Pöhls, J.-H.; Luo, Z.; Aydemir, U.; Sun, J.-P.; Hao, S.; He, J.; Hill, I. G.; Hautier, G.; Jain, A.; Zeng, X.; Wolverton, C.; Snyder, G. J.; Zhu, H.; White, M. A. First-principles calculations and experimental studies of $\mathrm{XYZ}_{2}$ thermoelectric compounds: detailed analysis of van der Waals interactions. J. Mater. Chem. A 2018, 6, 19502-19519.

(67) Roth, N.; Iversen, B. B. Solving the disordered structure of $\beta$ $\mathrm{Cu}_{2-x} \mathrm{Se}$ using the three-dimensional difference pair distribution function. Acta Crystallogr., Sect. A: Found. Adv. 2019, 75, 465-473.

(68) Weldert, K. S.; Zeier, W. G.; Day, T. W.; Panthöfer, M.; Snyder, G. J.; Tremel, W. Thermoelectric Transport in $\mathrm{Cu}_{7} \mathrm{PSe}_{6}$ with High Copper Ionic Mobility. J. Am. Chem. Soc. 2014, 136, 12035-12040.

(69) Sist, M.; Kasai, H.; Hedegaard, E. M. J.; Iversen, B. B. Role of vacancies in the high-temperature pseudodisplacive phase transition in GeTe. Phys. Rev. B 2018, 97, 094116.

(70) Xia, K.; Nan, P.; Tan, S.; Wang, Y.; Ge, B.; Zhang, W.; Anand, S.; Zhao, X.; Snyder, G. J.; Zhu, T. Short-range order in defective halfHeusler thermoelectric crystals. Energy Environ. Sci. 2019, 12, 15681574.

(71) Zeier, W. G.; Anand, S.; Huang, L.; He, R.; Zhang, H.; Ren, Z.; Wolverton, C.; Snyder, G. J. Using the 18-Electron Rule To Understand the Nominal 19-Electron Half-Heusler $\mathrm{NbCoSb}$ with $\mathrm{Nb}$ Vacancies. Chem. Mater. 2017, 29, 1210-1217.

(72) Isaacs, E. B.; Wolverton, C. Electronic Structure and Phase Stability of $\mathrm{Yb}$-Filled $\mathrm{CoSb}_{3}$ Skutterudite Thermoelectrics from FirstPrinciples. Chem. Mater. 2019, 31, 6154-6162.

(73) Luo, Z.-Z.; Cai, S.; Hao, S.; Bailey, T. P.; Hu, X.; Hanus, R.; Ma, R.; Tan, G.; Chica, D. G.; Snyder, G. J.; Uher, C.; Wolverton, C.; Dravid, V. P.; Yan, Q.; Kanatzidis, M. G. Ultralow Thermal Conductivity and High-Temperature Thermoelectric Performance in n-Type $\mathrm{K}_{2.5} \mathrm{Bi}_{8.5} \mathrm{Se}_{14}$. Chem. Mater. 2019, 31, 5943-5952.

(74) Hoang, K.; Tomic, A.; Mahanti, S. D.; Kyratsi, T.; Chung, D.Y.; Tessmer, S. H.; Kanatzidis, M. G. Role of K/Bi disorder in the electronic structure of $\beta-\mathrm{K}_{2} \mathrm{Bi}_{8} \mathrm{Se}_{13}$. Phys. Rev. B: Condens. Matter Mater. Phys. 2009, 80, 125112.

(75) Ohno, S.; Aydemir, U.; Amsler, M.; Pöhls, J.-H.; Chanakian, S.; Zevalkink, A.; White, M. A.; Bux, S. K.; Wolverton, C.; Snyder, G. J. Achieving $z T>1$ in Inexpensive Zintl Phase $\mathrm{Ca}_{9} \mathrm{Zn}_{4+x} \mathrm{Sb} 9$ by Phase Boundary Mapping. Adv. Funct. Mater. 2017, 27, 1606361.

(76) Bux, S. K.; Zevalkink, A.; Janka, O.; Uhl, D.; Kauzlarich, S.; Snyder, J. G.; Fleurial, J.-P. Glass-like lattice thermal conductivity and high thermoelectric efficiency in $\mathrm{Yb}_{9} \mathrm{Mn}_{4.2} \mathrm{Sb}_{9}$. J. Mater. Chem. A 2014, 2, 215-220.

(77) Ortiz, B. R.; Peng, W.; Gomes, L. C.; Gorai, P.; Zhu, T.; Smiadak, D. M.; Snyder, G. J.; Stevanović, V.; Ertekin, E.; Zevalkink, A.; Toberer, E. S. Ultralow Thermal Conductivity in Diamond-Like Semiconductors: Selective Scattering of Phonons from Antisite Defects. Chem. Mater. 2018, 30, 3395-3409.

(78) Schnepf, R. R.; Cordell, J. J.; Tellekamp, M. B.; Melamed, C. L.; Greenaway, A. L.; Mis, A.; Brennecka, G. L.; Christensen, S.; Tucker, G. J.; Toberer, E. S.; Lany, S.; Tamboli, A. C. Utilizing Site Disorder in the Development of New Energy-Relevant Semiconductors. ACS Energy Lett. 2020, 5, 2027-2041.

(79) Baranowski, L. L.; Zawadzki, P.; Lany, S.; Toberer, E. S.; Zakutayev, A. A review of defects and disorder in multinary tetrahedrally bonded semiconductors. Semicond. Sci. Technol. 2016, 31, 123004.

(80) Kim, J.; Larina, L.; Chung, S.-Y.; Shin, D.; Shin, B. Atomistic consideration of earth-abundant chalcogenide materials for photovoltaics: Kesterite and beyond. J. Mater. Res. 2018, 33, 3986-3998.

(81) Barabash, S. V.; Ozolins, V.; Wolverton, C. First-Principles Theory of Competing Order Types, Phase Separation, and Phonon Spectra in Thermoelectric $\mathrm{AgPb}_{m} \mathrm{SbTe}_{m+2}$ Alloys. Phys. Rev. Lett. 2008, 101, 155704.

(82) Xu, X.; Jiang, H. Anion order in perovskite oxynitrides $\mathrm{AMO}_{2} \mathrm{~N}$ $(\mathrm{A}=\mathrm{Ba}, \mathrm{Sr}, \mathrm{Ca} ; \mathrm{M}=\mathrm{Ta}, \mathrm{Nb})$ : a first-principles based investigation. RSC Adv. 2020, 10, 24410-24418.
(83) Zeljkovic, I.; Hoffman, J. E. Interplay of chemical disorder and electronic inhomogeneity in unconventional superconductors. Phys. Chem. Chem. Phys. 2013, 15, 13462-13478.

(84) Weisbuch, C.; Nakamura, S.; Wu, Y.-R.; Speck, J. S. Disorder effects in nitride semiconductors: impact on fundamental and device properties. Nanophotonics 2021, 10, 3-22.

(85) Ma, J.; He, J.; Mazumdar, D.; Munira, K.; Keshavarz, S.; Lovorn, T.; Wolverton, C.; Ghosh, A. W.; Butler, W. H. Computational investigation of inverse Heusler compounds for spintronics applications. Phys. Rev. B 2018, 98, 094410.

(86) He, J.; Amsler, M.; Xia, Y.; Naghavi, S. S.; Hegde, V. I.; Hao, S.; Goedecker, S.; Ozolinš̌, V.; Wolverton, C. Ultralow Thermal Conductivity in Full Heusler Semiconductors. Phys. Rev. Lett. 2016, $117,046602$.

(87) Hua, X.; Hegde, V. I.; Wolverton, C. Phase Stability and Ordering in Rock Salt-Based Thermoelectrics: $\mathrm{NaSbX}_{2}, \mathrm{AgSbX}_{2}$, and Their Alloys with $\mathrm{PbX}$ and $\mathrm{SnX}(\mathrm{X}=\mathrm{S}, \mathrm{Se}, \mathrm{Te})$. Chem. Mater. 2019, 31, 9445-9452.

(88) Faghaninia, A.; Yu, G.; Aydemir, U.; Wood, M.; Chen, W.; Rignanese, G.-M.; Snyder, G. J.; Hautier, G.; Jain, A. A computational assessment of the electronic, thermoelectric, and defect properties of bournonite $\left(\mathrm{CuPbSbS}_{3}\right)$ and related substitutions. Phys. Chem. Chem. Phys. 2017, 19, 6743-6756.

(89) Zhang, Y.; Ozoliņš, V.; Morelli, D.; Wolverton, C. Prediction of New Stable Compounds and Promising Thermoelectrics in the $\mathrm{Cu}-$ $\mathrm{Sb}-\mathrm{Se}$ System. Chem. Mater. 2014, 26, 3427-3435.

(90) Zhao, J.; Hao, S.; Islam, S. M.; Chen, H.; Tan, G.; Ma, S.; Wolverton, C.; Kanatzidis, M. G. Six Quaternary Chalcogenides of the Pavonite Homologous Series with Ultralow Lattice Thermal Conductivity. Chem. Mater. 2019, 31, 3430-3439.

(91) Khoury, J. F.; Hao, S.; Stoumpos, C. C.; Yao, Z.; Malliakas, C. D.; Aydemir, U.; Slade, T. J.; Snyder, G. J.; Wolverton, C.; Kanatzidis, M. G. Quaternary Pavonites $\mathrm{A}_{1+x} \mathrm{Sn}_{2-x} \mathrm{Bi}_{5+x} \mathrm{~S}_{10}\left(\mathrm{~A}^{+}=\mathrm{Li}^{+}, \mathrm{Na}^{+}\right)$: Site Occupancy Disorder Defines Electronic Structure. Inorg. Chem. 2018, $57,2260-2268$.

(92) Imasato, K.; Kang, S. D.; Snyder, G. J. Exceptional thermoelectric performance in $\mathrm{Mg}_{3} \mathrm{Sb}_{0.6} \mathrm{Bi}_{1.4}$ for low-grade waste heat recovery. Energy Environ. Sci. 2019, 12, 965-971.

(93) Wood, M.; Imasato, K.; Anand, S.; Yang, J.; Snyder, G. J. The importance of the $\mathrm{Mg}-\mathrm{Mg}$ interaction in $\mathrm{Mg}_{3} \mathrm{Sb}_{2}-\mathrm{Mg}_{3} \mathrm{Bi}_{2}$ shown through cation site alloying. J. Mater. Chem. A 2020, 8, 2033-2038.

(94) Lee, K.; Kaseman, D.; Sen, S.; Hung, I.; Gan, Z.; Gerke, B.; Pöttgen, R.; Feygenson, M.; Neuefeind, J.; Lebedev, O. I.; Kovnir, K. Intricate Short-Range Ordering and Strongly Anisotropic Transport Properties of $\mathrm{Li}_{1-x} \mathrm{Sn}_{2+x} \mathrm{As} s_{2}$. J. Am. Chem. Soc. 2015, 137, 3622-3630.

(95) Wang, J.; Yox, P.; Voyles, J.; Kovnir, K. Synthesis, Crystal Structure, and Properties of Three La-Zn-P Compounds with Different Dimensionalities of the Zn-P Framework. Cryst. Growth Des. 2018, 18, 4076-4083.

(96) Middey, S.; Ray, S.; Mukherjee, K.; Paulose, P. L.; Sampathkumaran, E. V.; Meneghini, C.; Kaushik, S. D.; Siruguri, V.; Kovnir, K.; Sarma, D. D. Glasslike ordering and spatial inhomogeneity of magnetic structure in $\mathrm{Ba}_{3} \mathrm{FeRu}_{2} \mathrm{O}_{9}$ : Role of $\mathrm{Fe} / \mathrm{Ru}$ site disorder. Phys. Rev. B: Condens. Matter Mater. Phys. 2011, 83, 144419.

(97) Bogicevic, A.; Wolverton, C.; Crosbie, G. M.; Stechel, E. B. Defect ordering in aliovalently doped cubic zirconia from first principles. Phys. Rev. B: Condens. Matter Mater. Phys. 2001, 64, 014106.

(98) Schmidt, A. M.; McGuire, M. A.; Gascoin, F.; Snyder, G. J.; DiSalvo, F. J. Synthesis and thermoelectric properties of $\left(\mathrm{Cu}_{y} \mathrm{Mo}_{6} \mathrm{Se}_{8}\right)_{1-x}\left(\mathrm{Mo}_{4} \mathrm{Ru}_{2} \mathrm{Se}_{8}\right)_{x}$ alloys. J. Alloys Compd. 2007, 431, $262-268$.

(99) McGuire, M. A.; Schmidt, A. M.; Gascoin, F.; Jeffrey Snyder, G.; DiSalvo, F. J. Thermoelectric and structural properties of a new Chevrel phase: $\mathrm{Ti}_{0.3} \mathrm{Mo}_{5} \mathrm{RuSe}_{8}$. J. Solid State Chem. 2006, 179, 21582163.

(100) Aydemir, U.; Zevalkink, A.; Bux, S.; Snyder, G. J. High temperature transport properties of $\mathrm{BaZn}_{2} \mathrm{Sn}_{2}$. J. Alloys Compd. 2015, $622,402-407$. 
(101) Kazem, N.; Hurtado, A.; Sui, F.; Ohno, S.; Zevalkink, A.; Snyder, J. G.; Kauzlarich, S. M. High Temperature Thermoelectric Properties of the Solid-Solution Zintl Phase $\mathrm{Eu}_{11} \mathrm{Cd}_{6-x} \mathrm{Zn}_{x} \mathrm{Sb} 12$. Chem. Mater. 2015, 27, 4413-4421.

(102) Zevalkink, A.; Chanakian, S.; Aydemir, U.; Ormeci, A.; Pomrehn, G.; Bux, S.; Fleurial, J.-P.; Snyder, G. J. Thermoelectric properties and electronic structure of the Zintl phase $\mathrm{Sr}_{5} \mathrm{In}_{2} \mathrm{Sb}_{6}$ and the $\mathrm{Ca}_{5-x} \mathrm{Sr}_{x} \mathrm{In}_{2} \mathrm{Sb}_{6}$ solid solution. J. Phys.: Condens. Matter 2015, 27, 015801 . 